\title{
Desafios da humanização no contexto do cuidado da enfermagem pediátrica de média e alta complexidade
}

Camila Aloísio Alves ${ }^{1}$

Suely Ferreira Deslandes ${ }^{2}$

Rosa Maria de Araújo Mitre 3

ALVES, C.A.; DESLANDES, S.F.; MITRE, R.M.A. Challenges of humanization in the context of pediatric nursing care of medium and high complexity. Interface - Comunic., Saude, Educ., v.13, supl.1, p.581-94, 2009.

This paper analyzes situations and contexts that favor or cause difficulties in relationships of welcoming and autonomy, including moments and contexts in which participation and coresponsibility are expressed in relationships between nursing and users and their accompaniers. A qualitative approach was used, with an ethnographic perspective and a three-month observation period. The study location was the pediatrics ward of a referral institute for Women's, Children's and Adolescents' healthcare, and the subjects were the nursing staff, users and accompaniers. The results indicated that the welcome was the initial point that was most observed, thus showing that this was a central element of the discussion. The levels of autonomy, participation and co-responsibility correlated with the duration of hospitalization, thus allowing relationships to be established with professionals and knowledge about care to be acquired. It was concluded that there are comprehension gaps in the humanization project for this service, involving management and care.

Keywords: Humanization of assistance. Welcoming. User embracement. Participation. Co-responsibility.
O presente artigo analisa as situações e contextos que propiciam ou dificultam as relações de acolhimento e autonomia, compreendendo os momentos e contextos em que o protagonismo e a corresponsabilidade são expressos na relação entre enfermagem, usuários e seus acompanhantes. Utilizou-se da abordagem qualitativa, por meio da perspectiva etnográfica e um período de observação de três meses. O local de estudo foi a enfermaria de Pediatria de um instituto de referência no cuidado da Saúde da Mulher, Criança e Adolescente, e os sujeitos foram equipe de enfermagem, usuários e acompanhantes. Os resultados apontam que o acolhimento foi $o$ princípio mais observado, mostrando-se como elemento central da discussão. Os níveis de autonomia, protagonismo e corresponsabilidade relacionaram-se ao tempo de internação, permitindo estabelecer relações com os profissionais e adquirir conhecimentos sobre a assistência. Conclui-se que existem lacunas na compreensão de um projeto de humanização para o serviço, contemplando gestão e cuidado.

Palavras-chave: Humanização da assistência. Acolhimento. Autonomia. Protagonismo. Corresponsabilidade.
${ }^{1}$ Instituto de Puericultura e Pediatria Martagão Gesteira, Universidade Federal do

Rio de Janeiro.

Rua das Palmeiras, 93/603. Botafogo, Rio de Janeiro, RJ, Brasil. 22.270-070 camila.aloisioalves @gmail.com 2,3 Instituto Fernandes Figueira, Fundação Oswaldo Cruz. 


\section{Introdução}

A humanização é um conceito polissêmico que se refere a reflexões e proposições sobre novas formas de agir, relações mais simétricas entre os sujeitos, por meio das quais o saber formal e científico, as experiências e saberes de pacientes e acompanhantes contribuem com a produção de conhecimento (Deslandes, 2006; Ayres, 2005).

No campo da saúde, o conceito de humanização é assumido oficialmente, por intermédio da Política Nacional de Humanização (Brasil, 2003), como uma proposta voltada para uma nova relação entre usuários, suas redes sociais, trabalhadores da saúde e gestores, apostando no trabalho coletivo na direção de um Sistema Único de Saúde (SUS) acolhedor e resolutivo.

A PNH possui alguns de seus princípios norteadores - o acolhimento, a autonomia, o protagonismo e a corresponsabilidade - que devem servir como base para as mudanças na relação entre profissionais e usuários. É uma política que coloca em questão as práticas em saúde, construídas com base no modelo biomédico, principal referencial epistemológico para a formação dos profissionais do campo (Brasil, 2003).

A crítica não está em apontar um modelo desumanizado, mas considerar que, ao longo do avanço científico, as práticas e as formas de reflexão superespecializaram cada parte do corpo humano, cindindo com a unidade dos sujeitos.

No âmbito da assistência pediátrica de média e alta complexidade, a cronicidade e gravidade dos casos colocam os profissionais frente à necessidade de desenvolver um fazer que considere: o uso de tecnologias de ponta, a incorporação constante de novos conhecimentos sobre doenças raras, limitações do desenvolvimento e maturação dos pacientes, além da relação com usuários e acompanhantes.

Para tanto, este trabalho buscou entender como a humanização podia ser percebida nas relações dialógicas entre a equipe de enfermagem, usuários e seus acompanhantes, privilegiando o acolhimento na assistência e a participação dos atores no cuidado. Seu objetivo é analisar as situações e contextos que propiciam ou dificultam as relações de acolhimento e autonomia, e compreender os momentos e contextos em que o protagonismo e a corresponsabilidade são expressos na relação entre enfermagem, usuários e seus acompanhantes.

\section{Acolhimento, corresponsabilidade, autonomia e protagonismo}

O acolhimento envolve a observação e escuta atenta, capaz de perceber as diversas demandas. Como conceito norteador da $\mathrm{PNH}$, pode ser entendido como princípio voltado para uma reflexão das práticas de saúde, pois reconhece o outro em suas diferenças a partir de um compromisso de responsabilização no encontro terapêutico. Além disso, a PNH toma-o também como dispositivo que opera mudanças concretas nos processos de trabalho e na gestão dos serviços (Brasil, 2006).

O acolhimento reacende a capacidade de alteração das práticas, pois convoca à análise e à revisão cotidiana das mesmas no âmbito do sistema de saúde, provocando incômodo ao salientar que promover saúde e cuidar são atos de corresponsabilidade entre os sujeitos.

Para Campos (2003), corresponsabilidade refere-se à construção de parcerias entre profissionais de saúde e usuários, elaborando alternativas para a condução de um caminho e considerando valores culturais dos diferentes coletivos.

A corresponsabilização implica produzir sentido para as diferentes ações dos sujeitos, além de proporcionar, por meio dos espaços coletivos, a manifestação do saber do outro. Considerar as redes de relações que envolvem os sujeitos e os valores que os permeiam é uma das reflexões que impacta na construção de uma responsabilização compartilhada e permite entender que o ser humano é um ser dependente de suas redes.

No cotidiano de uma enfermaria, um amplo conjunto de fatores envolve os profissionais, pacientes e acompanhantes. Considerar o que os permeia é o caminho para canalizar força para a produção de subjetividades protagonistas e responsáveis pelo cuidado. Valorizar o fortalecimento das redes de relações entre pacientes e profissionais da saúde, entre pacientes e seus familiares, é entender que essas redes de autonomia/dependência são importantes para a saúde (Soares, Camargo Jr., 2007).

A autonomia refere-se à capacidade de decisão dos atores baseada em informações, diálogo e 
valorização da rede de relações que permeiam os indivíduos. É um valor que se constitui de forma relativa, relacional e inseparável da dependência entre os sujeitos. Fortalecer a autonomia dos mesmos requer incentivo à rede de relações que os sustentam (Soares, Camargo Jr., 2007; Fabbro, 1999).

Ofertar e construir uma via de diálogo em que a autonomia possa ser exercida passa pelo conhecimento dos limites e das alternativas em jogo e requer pensar o indivíduo como dependente do coletivo. Para Soares e Camargo Jr., (2007, p.75) "ser humano autônomo é aquele que reconhece sua necessidade do outro em todos os planos - afetivo, intelectual, emocional".

O exercício da autonomia também está diretamente relacionado com a qualidade de informação disponibilizada durante o encontro terapêutico. É na medida em que paciente e acompanhante disponibilizam e compreendem o contexto em que estão inseridos, que a autonomia de ambos pode ser exercida de forma mais plena.

Compartilhar informações necessárias que envolvem o tratamento permite estabelecer uma participação construtiva no processo terapêutico, possibilitando aos sujeitos a manifestação de sua capacidade protagonista. O protagonismo é um princípio que implica: troca de aprendizados, construção de novos saberes, democratização de informações e desenvolvimento de ações em parceria (Rabello, 2002).

O ser protagonista refere-se à ação baseada nos conhecimentos existentes e naqueles que são aprendidos no contexto da assistência, atuando de forma construtiva e compartilhada nas relações entre usuários e profissionais de saúde.

Nesse sentido, o acolhimento como princípio base e que possibilita a construção de relações mais dialógicas, pode facilitar a produção de vínculos, entendendo o usuário como capaz de exercer sua autonomia e sua capacidade protagonista, compartilhando a responsabilidade pelo cuidado.

\section{Metodologia}

O presente trabalho elegeu a perspectiva etnográfica como meio para apreender os fenômenos elencados no estudo, já que permitiu a entrada no universo de diferentes sujeitos a partir de suas rotinas de trabalho e de cuidado (Creswell, 1997; Peirano, 1995). A etnografia é uma abordagem originária da antropologia que, de forma integrativa, leva em consideração as múltiplas dimensões do ser humano em sociedade (Laplantine, 2003).

A preocupação de um estudo com enfoque etnográfico incide em definir como um ethos de determinado grupo ou coletivo se atualiza na prática. O pesquisador que escolhe esta abordagem espera que, por meio da ampla e profunda observação do cotidiano do grupo a ser pesquisado, consigam se compreender as características do comportamento, dos costumes e das formas de vida de um coletivo (Creswell, 1997).

O local de estudo foi a Unidade Pediátrica de Internação (UPI) de uma instituição de referência no cuidado, ensino e pesquisa da Saúde da Criança, Adolescente e da Mulher, no Município do Rio de Janeiro, que possui 22 leitos para atender crianças e jovens entre as idades de zero a 18 anos.

Como sujeitos participantes de estudo, foram escolhidos: a equipe de enfermagem (técnicos e enfermeiros), pacientes e acompanhantes. Destaca-se a exclusão dos pacientes com osteogênese imperfeita que se internam para a realização de um tratamento inovador na área, com medicação intravenosa, o que exige uma preparação da equipe para receber esses pacientes. É uma internação programada, o que estabelece uma relação diferenciada com os profissionais da equipe de enfermagem.

A escolha pela enfermagem, como elemento central do grupo de sujeitos, partiu da compreensão de que a mesma mantém uma relação mais intensa e contínua com os pacientes e acompanhantes.

A entrada no campo foi, previamente, preparada por meio de um encontro com a chefia de enfermagem. A recepção foi positiva, demonstrando entusiasmo e apostando na perspectiva de contribuição para o trabalho desenvolvido na enfermaria.

O período de observação foi de três meses, contemplando diferentes horários dos plantões de trabalho, bem como as diferentes equipes e a movimentação de admissão e alta dos pacientes. 
A entrada no campo exigiu da pesquisadora, psicóloga e sanitarista, abrir-se a um mundo diferente de suas práticas. O contato com uma enfermaria pediátrica produziu um considerável estranhamento. Entretanto, no decorrer do trabalho de campo, foi possível estabelecer relações de parceria e troca, determinantes para a compreensão de lógicas e práticas de cuidado.

Segundo Laplantine (2003), para alcançar o homem em suas dimensões, é preciso dedicar-se à observação de fatos sociais cotidianos, que podem parecer pequenos, mas cuja significação só pode ser encontrada nos seus papéis assumidos dentro de um coletivo. Para acessar os fatos cotidianos e os papéis desempenhados pelos sujeitos da pesquisa, foi desenvolvido um roteiro, que norteou a entrada no campo com foco nas rotinas de cuidado da enfermagem, trocas de plantão, admissão e alta de paciente, dentre outras. O diário de campo foi utilizado como instrumento para o registro das observações, experiências e reflexões do estudo.

Após o período de imersão no campo, a maior riqueza de um trabalho etnográfico está relacionada à análise mais refinada dos dados iniciais, por meio da qual poderá ser verificada a ocorrência de novos indícios, de dados que ampliarão a capacidade de reflexão e que permitirão uma abordagem diversa (Peirano, 1995).

Primeiro foram revistas as observações registradas no diário de campo, depois estas foram mapeadas segundo as categorias de análise, respeitando os princípios da humanização e os objetivos desse trabalho. No item de análise e discussão, será apresentado o material analisado segundo as categorias elencadas no estudo, oriundas dos princípios da humanização, e trechos do diário de campo serão descritos com o objetivo de validar as interpretações. Além disso, será desenvolvida uma caracterização da enfermaria com objetivo de ilustrar o campo de estudo.

Cabe destacar que esse trabalho foi submetido à aprovação no Comitê de Ética em Pesquisa do Instituto Fernandes Figueira (IFF/Fiocruz) e aprovado sob o número 0012/028.

\section{Caracterização da enfermaria}

A enfermaria possui 11 boxes, contendo: dois ou três leitos, cadeiras dos acompanhantes, pertences dos pacientes, como roupas e brinquedos, além de televisão e aparelho de DVD.

A enfermagem compõe equipes que contam, durante a semana, com dois enfermeiros diaristas e cinco plantonistas (entre enfermeiros e técnicos de enfermagem). Aos finais de semana, o quantitativo diminui para cinco plantonistas, sendo a carga horária do plantão de $12 \times 60$ horas.

$\mathrm{Na}$ parte da manhã, as rotinas estavam concentradas nos procedimentos médicos e de enfermagem e nas atividades dos demais profissionais, como fisioterapeutas, nutricionistas, assistentes sociais e voluntários do Projeto da Biblioteca Viva4.

No horário do almoço, havia uma divisão da equipe de enfermagem para suprir o cuidado na enfermaria e os acompanhantes desciam para se alimentar no refeitório. Por meio dessa dinâmica, a parte da tarde contava com um ambiente mais tranquilo, em que a enfermagem conseguia estar mais próxima dos pacientes e acompanhantes. Na parte da manhã, a sequência de procedimentos (banho, medicação, limpeza de curativos etc.) era automatizada para conseguir ser realizada dentro do tempo hábil. Com relação ao período noturno, a tranquilidade era maior ainda, pois apenas a equipe de enfermagem ficava completa e os médicos eram representados por seus plantonistas.

\author{
${ }^{4}$ Projeto que tem como \\ objetivo promover um \\ espaço de estímulo à \\ criatividade e organização \\ do pensamento das \\ crianças internadas ou em \\ atendimento \\ ambulatorial. Os espaços \\ de leitura são compostos \\ por livros de literatura \\ infantil e juvenil, com a \\ mediação de leitura para \\ bebês, crianças, jovens e \\ seus acompanhantes, \\ respeitando as restrições \\ de contato e cuidados \\ especiais (http:// \\ www.iff.fiocruz.br/ \\ textos/prog_bibiviva.htm)
}


Durante a pesquisa, as mães dos pacientes representaram a maioria dos acompanhantes, enquanto a minoria era de parentes da família e amigos. Os pais frequentavam mais a enfermaria em momentos de visita. Apenas o pai de uma paciente mantinha uma relação de maior permanência na enfermaria, substituindo a mãe em alguns dias. Com relação ao horário de visitas, logo após o início do estudo, foram ampliados para todos os dias da semana.

Dentre os pacientes internados, a maior parte era representada por bebês e crianças de até três anos. Em segundo lugar, estavam as crianças com idades entre cinco a dez anos. Ao todo, apenas três adolescentes passaram pela internação no período. Todos os pacientes internados e observados no período apresentavam patologias graves e crônicas, como as neurológicas e de origem genética.

\section{Análise e discussão}

Observar a materialização de princípios presentes e defendidos pela $\mathrm{PNH}$ no contexto estudado foi uma tarefa que exigiu um olhar diferenciado para a rotina de trabalho da enfermagem e uma compreensão que procurasse entender mais detalhadamente os meandros existentes nas relações entre esta equipe, os pacientes e seus acompanhantes.

\section{Acolhimento}

Comparativamente com os demais princípios da humanização, o acolhimento foi o princípio que mais facilmente foi observado nas relações entre enfermagem, pacientes e acompanhantes, bem como o seu inverso, ou seja, as situações de não acolhimento.

Foi possível observar situações em que os profissionais procuraram desenvolver um cuidado diferenciado para as crianças, respeitando o cuidado da mãe e mantendo uma interação com a criança durante o banho, a troca de curativos e a administração de dietas.

\footnotetext{
Ao final de uma manhã foi realizada uma visita no leito de uma paciente que apresentava muitas feridas espalhadas pelo corpo devido a sua enfermidade. Conforme os curativos foram sendo tirados, a criança chorava e gritava muito. Diante do desconforto da paciente, a reação da enfermeira foi cobri-la novamente, num movimento de compreensão do constrangimento, ainda que a paciente não verbalizasse uma só palavra.

(Diário de campo, 09/06/08)
}

A situação de internação de uma criança ou adolescente, em geral, é um momento delicado para a família e que requer reconfiguração da rotina de vida e assimilação do processo de adoecimento. $O$ momento da hospitalização é uma experiência marcada pela ruptura com o cotidiano da escola, dos amigos, da família e das brincadeiras. "A atividade e a liberdade características da infância são substituídas pela passividade, deixando-se poucas opções para que a criança faça escolhas" (Mitre, 2006, p.286).

Essa modificação produz um estranhamento da experiência de hospitalização que diferirá entre pacientes e familiares. As referências do contexto de vida da criança e do adolescente são substituídas pelas paredes claras, procedimentos invasivos, medicamentos, maquinários, novos termos e palavras e sensação de dor e sofrimento (Mitre, 2006).

Nos casos de pacientes pediátricos crônicos e agudos, a relação com o adoecimento se modifica e novos conhecimentos são aprendidos pela criança. Muitas cresceram convivendo com situações de vida limitantes e aprendendo a incorporar o espaço hospitalar ao seu cotidiano.

Destaca-se a diferença existente entre a apropriação do espaço hospitalar e o estabelecimento de vínculos pelos pacientes internados há mais tempo e seus acompanhantes, em detrimento daqueles que estavam recém-admitidos. 
Ao longo dos plantões, as acompanhantes que estão há mais tempo internadas mantém relações de amizade e discutem os casos de suas crianças, além de apoiarem-se. Em caso de necessidade de algum insumo ou orientação sabem onde procurar. Em contraposição, uma mãe recém admitida permanecia com dúvidas em relação ao caso de sua filha, o que a deixava desorientada. (Diário de campo, 16/06/08 e 02/07/08)

Entre os primeiros, puderam ser observadas relações de afeto e de parceria, desenvolvidas com o tempo, além de terem adquirido maior conhecimento sobre o funcionamento do hospital e sobre a assistência, tornando o cotidiano menos hostil. Entretanto, para os segundos, a recente experiência gerava expressões de medo e insegurança diante do desconhecido mundo hospitalar. Cabe destacar a existência do grupo de mães, que propicia a integração e a troca de experiências por meio de encontros semanais.

Como veículo que propicia o acesso aos saberes de pacientes e acompanhantes, o diálogo foi observado em diversas situações na prestação da assistência. Ainda que os pedidos de mães e acompanhantes não tenham sido respondidos prontamente em função do excesso de trabalho para uma equipe reduzida, elas foram atendidas na totalidade dos casos, seja fornecendo-se algum insumo, seja para auxílio à beira do leito, como na troca de curativos e orientações gerais.

Segundo Coa e Pettengill (2006), o papel da enfermeira em Pediatria é de defensora e educadora da criança, sendo de sua responsabilidade prepará-la e informá-la sobre o procedimento ao qual será submetida. Ainda que haja discordâncias entre a definição desse papel e perfil, sabe-se que, na relação com a criança internada, vários fatores envolvem a condução do caso, passando pela rede de relacionamentos que se estabelece. Despontando no primeiro nível de relacionamento, estão os acompanhantes - na grande maioria representados pela figura da mãe -, que passam a desempenhar um papel fundamental para a recuperação do paciente.

A experiência das mães na assistência aos filhos é permeada pela dinâmica das atividades do cuidado. Muitas delas, sobretudo aquelas que estavam há mais tempo com seus filhos internados, já adquiriram conhecimentos sobre os cuidados, desde o banho até a troca de curativos e monitoramento de equipamentos.

Contudo, como esse cuidado não é técnico e especializado, ocorreram problemas que precisaram de correções e ajustes segundo a avaliação da enfermagem. Em muitos casos, o diálogo prevaleceu como instrumento de contato para esclarecimentos, reduzir fontes de problema e minimizar os conflitos.

Durante uma conversa entre uma acompanhante e a enfermeira foram solucionados problemas referentes ao curativo que a mãe fizera. Foi explicada à mãe a seqüência dos passos para a realização do curativo, e a mesma tanto se posicionou crítica ao conhecimento, quanto parceira da enfermeira. (Diário de campo, 30/08/08)

O desenvolvimento do cuidado dos acompanhantes não partia de uma opção dos mesmos, eles foram sendo inseridos na rotina, aprendendo e atuando. Não existia um projeto terapêutico que integrasse os saberes e delimitasse os graus de atuação dentro de cada esfera do cuidado.

A mudança de postura dos profissionais, englobando a família e/ou o acompanhante no universo da internação, é apontada por Collet e Rocha (2004) como uma modificação do foco antes centrado apenas na criança e sua patologia para aquele centrado na família. A assistência pediátrica passou a ter, como meta, a família, considerada a unidade primária do cuidado, não desconsiderando os avanços tecnológicos conquistados, mas agregando valor ao incluí-la na perspectiva do cuidado, cabendo à enfermagem entender o indivíduo e prestar assistência.

O primeiro reflexo dessa mudança refere-se à organização do trabalho, que precisa ter um novo arranjo em âmbito teórico e prático. A permanência dos pais vem imprimindo outra dinâmica no processo assistencial, pois se abre a oportunidade para que aprendam algumas habilidades técnicas e ampliem o conhecimento sobre o funcionamento do hospital e da terapêutica (Lima, Rocha, Scochi, 1999). 
A presença do familiar no contexto da internação da criança e do adolescente representou um avanço para as relações entre os usuários com o hospital, mas como iniciativa isolada não dá conta da necessidade de se compreender a dinâmica que envolve o processo de adoecimento da criança e do adolescente. A presença do acompanhante precisa ser seguida de um projeto terapêutico de integração do cuidado, pois seu sentido relaciona-se à doença do paciente.

Nesse momento entram em jogo as habilidades e capacidades de comunicação, diálogo, acolhimento de diversas demandas e oportunidades de expressão da autonomia. No contexto observado, essas habilidades e capacidades estavam sujeitas à sensibilidade individual dos profissionais, o que tornou o encontro entre estes e os acompanhantes sujeito à sorte das características como afinidade, paciência e tolerância de ambas as partes.

Cabe destacar que essa enfermaria conta com o trabalho de profissionais que apresentam formações distintas no campo da saúde (médicos, enfermeiros, técnicos de enfermagem, assistentes sociais, fisioterapeutas, psicólogos, nutricionistas e terapeutas ocupacionais). Esse fato tanto privilegia que o paciente receba um atendimento permeado por diversos olhares, quanto desafia a equipe a construir um trabalho que favoreça a integração interdisciplinar.

A enfermagem - como equipe para qual são delegadas, na grande maioria dos casos, as funções de informar e conduzir o cotidiano da assistência - vivenciou, em muito casos, momentos de dúvida e de nebulosidade na definição de papéis dentro da enfermaria, seja na relação entre os profissionais de saúde, seja na relação entre os acompanhantes.

Para Collet e Rocha (2004, p.194),

[...] Tudo fica subentendido nessa relação. A partir do momento que a mãe adentra no mundo do hospital, não tem claro qual a natureza ou extensão de sua participação no cuidado, vai descobrindo no cotidiano da assistência. Existe cooperação na assistência, contudo, fica caracterizada uma relação entre enfermagem e mães mais de dominaçãosubordinação do que de colaboração, de co-participação no cuidado à criança hospitalizada.

Compartilhar os cuidados com a mãe é desejado pela enfermagem, mas isso é feito sem uma coparticipação materna, estabelecendo relações de mando. O diálogo nem sempre faz parte dos instrumentos da enfermagem para negociar os cuidados com a mãe e para acolher as demandas do serviço (Collet, Rocha, 2004).

Durante uma consulta ambulatorial, mãe e filha foram encaminhadas para a internação, dado a gravidade do caso da menina. Ao subirem para o andar da enfermaria, ficaram seis horas esperando, sem receber qualquer tipo de informação e alimentação. (Diário de campo, 16/06/08)

Ao se admitir a paciente, observou-se o relato da mãe que dizia ter tentado contato com profissionais e nenhuma resposta ou encaminhamento recebera.

O diálogo falhou, também, em situações de dúvidas sobre a condução do caso pelas equipes médica e de enfermagem. Uma das mães, com pouco tempo de internação e em busca pelo diagnóstico da filha, não conseguiu saber informações mais claras sobre o que estava acontecendo. Por não encontrar uma via clara de diálogo, optou por não verbalizar suas dúvidas. Tempos depois, essa mesma mãe conseguiu se sentir mais habilitada para emitir questionamentos à equipe. O diálogo também não ocorreu em situações como:

Durante a passagem de plantão, o pai de uma criança recém internada adentrou a enfermaria, muito nervoso, em busca de informação sobre o caso da filha. O técnico de enfermagem ao presenciar a situação disse: "o senhor aguarda lá fora, até o procedimento da sua filha acabar".. e foi encaminhando-o para fora da enfermaria em meio aos prantos paternos. (Diário de campo, 16/06/08) 
Para Sabatés e Borba (2005), é um dever da enfermeira fornecer informação completa, apurada, correta e clara sobre as condições e as reações à doença, o tratamento da criança, e verificar como os pais compreendem a situação. As autoras apontam que há um descompasso entre a satisfação dos pais pela informação recebida e a percepção das enfermeiras acerca do entendimento dos pais sobre o fornecimento das informações.

Para além da informação clara e objetiva, está a necessidade de se estabelecer um espaço de diálogo, que habilite os diferentes atores a expressarem suas dúvidas e sentimentos. Esse espaço não pode estar atrelado ao tempo de internação, mas instituído como forma de gestão do cotidiano do serviço. Ter um espaço de diálogo representa uma forma de acolher o outro e sua demanda.

Em internações prévias, uma acompanhante sofreu uma queda da cadeira. Como sofria de dores nas costas, pediu que alguém trocasse a cadeira antiga que encontrou ao reinternar seu sobrinho. Diante da solicitação uma enfermagem falou: "se ela tem problemas, melhor não ficar por aqui". (Diário de campo, 16/06/08)

A troca ocorreu dias depois, pois a equipe colocava como problema ter de transferir uma cadeira de outro boxe, o que poderia danificá-la. Até a transferência da cadeira se efetivar, sucederam-se dias de um relacionamento distante entre a enfermagem e a acompanhante, que julgava ser simples a resolução de seu problema.

\section{Autonomia}

As situações que mais caracterizaram o princípio da autonomia foram: as referentes aos cuidados das mães em relação aos seus filhos, as conversas com as equipes por meio da apropriação do espaço e do processo de tratamento. As mães que estavam há mais tempo na enfermaria conseguiram exercer um maior grau de autonomia no exercício do cuidado por terem adquirido conhecimentos sobre a assistência em detrimento daquelas com pouco tempo de internação.

Durante o movimento inicial da manhã, no horário de banho das crianças, muitos acompanhantes, prontamente, encaminhavam-se para o banheiro ou realizavam a higiene do paciente ao leito. (Diário de campo, 25/05/08)

Ao chegar a alimentação dos pacientes, alguns acompanhantes de crianças dependentes de alimentação enteral, iniciavam os procedimentos necessários como lavar as mãos, e ir passando a alimentação, observando o andamento da absorção dos pacientes. (Diário de campo, 29/05/08)

Ao finalizar a higiene da criança, uma das acompanhantes conduziu a troca do curativo. Houve extravasamento do líquido abdominal e diante da dificuldade de resolver o problema, dirigiu-se à enfermeira solicitando ajuda: "já tentei limpar o curativo, mas continua a sair aquele líquido, não sei o que fazer... e ela (paciente) está chorando muito". (Diário de campo, 27/06/08)

Para os pacientes, o cuidado pode ser ofertado por vários atores que os envolvem durante a assistência, e a ação de um não minimiza os efeitos do outro, mas agregam valor e benefícios. Para os pacientes, podem ser traduzidas como fontes de cuidar e de sentir-se cuidado (Gonzaga, Arruda, 1998): a presença dos pais, dos profissionais da saúde, profissionais do hospital, de visitas e de companheiros de quarto.

Contudo, as fontes do não cuidar remetem às atitudes de desinteresse manifestadas pelos profissionais, tais como executar os procedimentos de forma fria e mecânica. Todas essas ações contribuem para o aumento da angústia e estresse que o paciente está vivenciando no momento da hospitalização (Gonzaga, Arruda, 1998). 
Durante a passagem de um cateter intravenoso profundo, procedimento invasivo feito na sala de procedimentos, a criança estava extremamente assustada e com muito medo. A enfermagem conduziu o processo, mas em nenhum momento foi explicado para a paciente, que já tinha 12 anos, o motivo do procedimento. Quando foi preciso fazer um ajuste do cateter, a paciente novamente ficou amedrontada. (Diário de campo, 27/06/08 e 02/07/08)

Essa observação exemplifica falhas no diálogo entre a enfermagem e o paciente, e entre a enfermagem e a equipe médica, pois em alguns casos a enfermagem executa um procedimento solicitado pelo médico sem averiguar a compreensão da criança e/ou da família sobre a situação.

\section{Protagonismo}

O protagonismo também esteve atrelado ao tempo de internação. Destaca-se a capacidade de negociação de uma paciente de 15 anos, com várias internações recorrentes desde o início de sua vida.

Para a internação de uma criança a enfermeira solicitou a uma colega que pegasse um saturímetro. A colega encontrou um aparelho disponível com a paciente de 15 anos e solicitou que emprestasse para outra criança. A adolescente disse: "não me importo de emprestar, desde que ele volte para mim a noite... Não posso dormir sem o saturímetro". (Diário de campo, 02/07/08)

Em outro caso, a mãe utilizou seus conhecimentos sobre as reações da filha para solicitar à fisioterapeuta que trocasse o horário do atendimento, atuando como mediadora entre a técnica e a filha. A proposta de trabalho da fisioterapia comprometia o estado de saúde da sua filha, pois iria ser feita antes da passagem da dieta, afetando a disposição da criança para o cuidado.

Uma outra forma de denúncia de desarticulação entre as equipes fez de uma mãe protagonista do cuidado de sua filha, pois utilizou seu conhecimento sobre o funcionamento do serviço para solicitar maior atenção ao quadro da paciente, exigindo, criticamente, integração da equipe.

A capacidade de exercer o protagonismo nas relações no contexto observado passa também por uma "habilitação" da expressão e da fala conquistada por meio do maior tempo de permanência no serviço. Além disso, o protagonismo exercido pelas mães não vem acompanhado de outra relação protagonista da enfermagem.

${ }^{5}$ Programa interdisciplinar, que utiliza o brincar como estratégia de intervenção no adoecimento e hospitalização infantil, por meio da criação de espaços lúdicos dentro das enfermarias pediátricas e junto aos ambulatórios, destinado às crianças, suas relações com os acompanhantes e equipe de saúde. Funciona regularmente há 14 anos, duas vezes enfermaria de Pediatria. Como os papéis no cuidado com a criança não estão claramente definidos (mães e enfermagem se alternam em certas tarefas), a capacidade protagonista, tanto da mãe quanto da enfermagem, não se manifesta com a mesma facilidade. O que mais facilmente se observou foi uma relação de protagonismo da enfermagem versus um posicionamento antagonista da mãe.

Entretanto, os momentos de maior protagonismo vivenciado pelas crianças internadas estavam relacionados à entrada da equipe do Programa Saúde Brincar ${ }^{5}$. Nesse momento, a expressão das crianças mudava e era dada a chance de outro tipo de comunicação por meio do lúdico. O ambiente hospitalar, o desconforto dos procedimentos e as experiências advindas dos mesmos encontravam outro canal de comunicação. 


\section{Corresponsabilidade}

Já em relação à corresponsabilidade, o mesmo foi observado em relação ao cuidado dos pacientes desenvolvido somente pela mãe/acompanhante ou enfermagem e em parceria entre os dois atores, demonstrando que a prestação do cuidado ao paciente é central e todas as relações giram ao redor das práticas assistenciais. Por intermédio do exercício da técnica, acompanhantes e enfermagem vivenciaram situações de proximidade e de distanciamento em suas relações.

Transmitir conhecimentos técnicos aos acompanhantes gerou problemas a serem gerenciados pelas equipes, pois abriram caminho para a ocorrência de erros e colocaram a enfermagem em alerta diante dos fatores que envolviam o paciente. Existia ${ }_{\perp}$ como norma entre a equipe, a obrigação técnica dos profissionais, e somente eles, de fornecer os cuidados aos pacientes. Contudo, diante do acúmulo de trabalho da enfermagem, contar com alguém que conseguisse ministrá-los, como os acompanhantes, produzia uma situação paradoxal de ajuda.

Entretanto, para os acompanhantes, as ações do cuidado não eram vistas como obrigação, pois existiam dias em que se queria fazer tudo e outros dias em que nada se queria fazer. A confluência dessas duas situações gerava ambiguidade no trabalho e conflito nas relações, comprometendo o andamento das rotinas.

O investimento na relação entre a enfermagem, usuários e seus acompanhantes - a partir de fatores como o acolhimento pautado pelo diálogo, o conhecimento que se adquire e os papéis que são assumidos no contexto da internação - poderá incentivar o protagonismo e a autonomia das crianças e dos seus acompanhantes.

Nesse sentido, Castro (2001) traz à luz um novo conceito sobre a infância por meio de sua teoria da ação, a qual enfatiza a importância de legitimar a criança como um ser capaz de exercer seus direitos mediante sua capacidade de ação no mundo e de compreensão do mesmo. A autora considera que a infância possui distintas possibilidades de intervenção a partir das diferentes categorias sócioetárias e das inserções nos espaços de convivência.

Com isso, a autora questiona a visão desenvolvimentista sobre a criança como um ser em processo de formação e que, portanto, necessita de normas para que o débito social e cultural possa ser saldado por meio de ações educativas. Como um ser incompleto e desprotegido, a criança teria, na figura do adulto, um porta-voz de seus desejos e direitos.

A valorização do saber dos pacientes pediátricos sobre seu processo de adoecimento e sobre as relações experienciadas no contexto de internação são tão importantes quanto a experiência dos familiares e acompanhantes. O direito de expressão destas crianças pode fornecer valiosos subsídios para que as práticas em saúde possam ser repensadas em prol de uma assistência mais integral e acolhedora. Entre as crianças observadas, ficou clara a existência de possibilidades de expressão do corpo e da fala sobre o que estava sendo experienciado, demonstrando os diferentes canais de comunicação.

Durante a aspiração de secreções de uma paciente portadora de uma síndrome grave, que a impossibilitava de falar, suas expressões faciais manifestavam o desconforto da situação. Essa mesma paciente também expressava contentamento ao ver a mãe e profissionais voltados para seu cuidado. (Diário de campo, 29/05/08)

A partir dessa compreensão, é possível construir relações em saúde que não sejam pautadas pelo assujeitamento e pelo controle, e apostar na capacidade do paciente de expressar, criar e reinventar normas que possibilitem a administração, de forma autônoma, da sua margem de risco na vida, ampliando as capacidades de enfrentamento da doença junto às relações que lhe são mais importantes.

O reconhecimento, por parte da equipe de saúde, das condições nas quais se encontram o corpo e a subjetividade do paciente é o passo inicial para a incorporação de uma nova forma de compreensão do acolhimento, considerando os fatores que envolvem a vida do paciente.

Assume-se, como proposta, tomar o cuidado como valor (Pinheiro, 2007), apreendendo-o como uma ação integral que tem significados e sentidos voltados para a compreensão da saúde como direito 
ao tratamento médico e das demais especialidades, possibilitando ao paciente participar ativamente das decisões sobre a condução de seu próprio caso.

O cuidado começa quando se inicia uma relação dialógica entre paciente e profissional de saúde que transcenda o simples jogo de perguntas ativas do médico e respostas passivas do paciente, em direção à construção de um campo de trocas, em que ao saber do médico incorporam-se as experiências do indivíduo. Com isso, é possível se estabelecerem relações pautadas pela parceria de pessoas que têm, como objetivo, encontrar o caminho mais curto que as leve ao restabelecimento da saúde.

Caprara e Franco (1999) salientam a necessidade de se superar o modelo informativo, que repassa a informação, e o modelo paternalista, que protege o paciente da sua própria doença, para um modelo de comunicação que inclua outros atores importantes na vida dos pacientes.

Para Deslandes (2004a), as possibilidades comunicacionais estão relacionadas à posição social que os indivíduos ocupam. Na relação entre médicos e pacientes existe, historicamente, uma diferenciação entre o lugar e valor de suas falas.

Contudo, a construção de uma via de diálogo inicia-se por meio do reconhecimento do lugar do paciente como sujeito na relação. Segundo Deslandes (2004b), o movimento necessário para mudar essa lógica da atenção em saúde não passa só pela incorporação de um novo entendimento acerca dos pacientes e de suas vivências, mas de uma mudança que trabalhe, também, com vistas para a cultura organizacional, a qual concentra as relações de saber-poder, de gênero e status social. Esses fatores são capazes de alimentar determinadas formas de relacionamento entre os atores nas instituições.

O cuidado assumido como valor (Pinheiro, 2007) propõe que se reconheça o ethos do ser cuidado e do cuidador, o que requer incluir, na relação, a dimensão da vida individual, com seus hábitos e costumes, e a vida em comunidade, sendo ambas promotoras de identidade nos sujeitos. É ser capaz de incorporar o ethos do outro, num processo de alargamento de si mesmo e fazendo daquele momento terapêutico um momento único de contato e diálogo.

Para tanto, destacam-se duas situações que servem como exemplos breves para uma reflexão sobre a possibilidade de abertura à proposta de humanização pelo coletivo. Uma delas é a de uma paciente que, com poucos meses de vida, foi internada no instituto, apresentando uma doença genética rara e que compromete todo seu desenvolvimento, pois é completamente dependente de equipamentos. A mãe, de origem nordestina, vinha tentando sua transferência já há algum tempo e, durante o trabalho de campo, verbalizou esse desejo de estar com a filha perto do restante da família. A dificuldade estava em conseguir um transporte aeroviário que fosse habilitado à transferência de paciente com seus equipamentos. Meses se passaram até que fosse viabilizado o transporte por meio da Força Aérea Brasileira. Para tanto, a equipe do Departamento de Pediatria, incluindo médicos, enfermeiros e demais profissionais, mobilizou-se para promover essa transferência da maneira mais segura e acolhedora possível. A mãe pôde atuar como corresponsável no processo de transferência, tendo reconhecida, pela equipe, sua necessidade de proporcionar um cuidado para a filha amparada pela rede familiar presente no outro estado.

O segundo caso traz o falecimento de uma paciente cuidada pelo serviço por muitos anos que, depois de uma cirurgia cardíaca, voltou dependente de equipamentos e com pouca capacidade de interação com as outras pessoas, inclusive com a mãe. Sua história era permeada pelo afeto e carinho que os profissionais já possuíam pela menina. Ao final do trabalho de campo, ocorreu seu falecimento, e a forma como médicos e enfermeiros conduziram o processo do luto da equipe e da mãe merece destaque. Primeiramente, ao perceberem que a paciente estava falecendo, conseguiram acolher a mãe e conduziram, de forma corresponsável, os cuidados clínicos, além de terem procurado manter a calma do setor para que os demais acompanhantes não ficassem abalados. Com a comprovação do óbito, reintegraram a mãe ao boxe, onde estava o leito da filha, mantendo uma postura de acolhimento à dor materna. Ao final, apesar da dor de todos os presentes, profissionais e a mãe apoiaram-se e abriram-se à sensibilidade de cada um dos sujeitos. A mãe foi acolhida e, em parceria com os profissionais de saúde, envolveu-se corresponsavelmente pelos últimos cuidados com a criança.

Pode-se compreender que o coletivo observado não está anestesiado da chance de reverter os distanciamentos existentes entre as categorias profissionais e os acompanhantes, e alcançar um modelo de trabalho que invista no arranjo interdisciplinar da equipe, pois, em ambos os casos, foram construídas parcerias envolvendo acolhimento e corresponsabildade. 
É por meio do processo de trabalho que se pode experienciar uma ética definidora de práticas em saúde (Deslandes, 2007), na qual se articulam os conhecimentos adquiridos ao longo do tempo de formação profissional com posturas e atitudes em relação ao outro, a si mesmo e a própria relação terapêutica.

O diferencial entre tornar essa conversa um meio de apenas informar, questionar e responder está em tornar o acolhimento do outro a mola-mestra da lógica tecnoassistencial, a partir da sua potência em conectar uma conversa à outra (Teixeira, 2007).

O acolhimento como elemento central dessa discussão implica assumir um caráter de produção de mudanças para a proposição de reformulação do modelo de cuidado. Estas podem ser pensadas na medida em que, antes do manejo específico da técnica, exame ou procedimento, tem algo que modula a relação que está vinculado ao contato, à escuta sincera e aberta e à valoração do saber do outro.

\section{Conclusão}

Os resultados encontrados com o estudo etnográfico demonstram que o projeto de trabalho pautado na humanização - considerando seus princípios fundamentais: acolhimento, autonomia, protagonismo e corresponsabilidade - não se efetiva nas relações tecidas entre equipe, pacientes e acompanhantes.

Os níveis de autonomia, protagonismo e corresponsabilidade estiveram atrelados à capacidade de se estabelecerem relações com os profissionais desenvolvidas com o tempo de internação. Quanto maior o tempo de internação do paciente, mais estreitos eram os laços com a enfermagem e maior era a aquisição de conhecimentos sobre os cuidados com as crianças.

Existem lacunas na compreensão da proposta de um projeto de humanização para o serviço, que contemple sua gestão e as relações entre pacientes e seus acompanhantes. O imaginário da humanização que permeia a equipe é de prestar uma atenção de qualidade sem discussão sobre como a mesma será prestada e sem refletir sobre os obstáculos e possibilidades de mudança das práticas.

A atuação de um projeto de Educação Continuada, que integrasse os conhecimentos de acompanhantes com os de profissionais, e os preparasse para a construção coletiva das práticas na enfermaria, poderia contribuir para o estabelecimento de relações mais simétricas.

Como lacunas a serem preenchidas por estudos futuros, deve-se aprofundar a discussão de estratégias que materializem a incorporação dos princípios da humanização para a equipe e na relação com usuários e acompanhantes.

É preciso consolidar as iniciativas de acolhimento já desenvolvidas nesse coletivo pelos profissionais, enquanto um projeto de gestão da assistência, mas também permitir que os demais princípios sejam incorporados por intermédio de novas relações, com sujeitos implicados e produtores de saúde.

\section{Colaboradores}

Camila Aloisio Alves foi responsável pela pesquisa de campo, análises e redação do texto. Suely Ferreira Deslandes e Rosa Maria de Araújo Mitre orientaram o projeto e a elaboração do manuscrito. 


\section{Referências}

AYRES, J.R.C.M. Hermenêutica e humanização das práticas de saúde. Cienc. Saude Colet., v.10, n.3, p.549-60, 2005.

BRASIL. Ministério da Saúde. Acolhimento nas práticas de produção de saúde. 2.ed. Brasília: Ministério da Saúde, 2006. (Textos Básicos de Saúde, série B)

Ministério da Saúde. HumanizaSus: política nacional de humanização humanização como eixo norteador das práticas de atuação e gestão em todas as esferas do SUS. Brasília: Ministério da Saúde, 2003.

CAMPOS, G.W.S. Saúde Paidéia. São Paulo: Hucitec, 2003.

CAPRARA, A.; FRANCO, A.L.Z. A relação paciente-médico: para uma humanização da prática médica. Cad. Saude Publica, v.15, n.3, p.647-54, 1999.

CASTRO, L.R. Da invisibilidade à ação: crianças e jovens na construção da cultura. In: . (Org.). Crianças e jovens na construção da cultura. Rio de Janeiro: Nau Editora/Faperj, 2001. p.19-46.

COA, T.F.; PETTENGILL, M.A.M. Autonomia da criança hospitalizada frente aos procedimentos: crenças da enfermeira pediatra. Acta Paul. Enferm., v.19, n.4, p.433-8, 2006.

COLLET, N.; ROCHA, S.M.M. Criança hospitalizada: mãe e enfermagem compartilhando o cuidado. Rev. Latinoam. Enferm., v.12, n.2, p.191-7, 2004.

CRESWELL, J.W. Five qualitative traditions of inquiry. In: and researcher design. London: Sage Publications, 1997. p.41-72.

(Org.). Qualitative

DESLANDES, S.F. O cuidado como valor e ethos da prática em saúde. In: PINHEIRO, R.; MATTOS, R.A. (Orgs.). Razões públicas para a integralidade em saúde: o cuidado como valor. Rio de Janeiro: IMS/UERJ/CEPESC/Abrasco, 2007. p.385-96. médica. In: $\quad$ (Org.). Humanização dos cuid.
práticas. Rio de Janeiro: Fiocruz, 2006. p.33-47.

Humanização: revisitando o conceito a partir das contribuições da sociologia

A humanização e a construção política do lugar de sujeito no processo comunicacional. Cienc. Saude Colet., v.9, n.1, p.15-29, 2004 a.

A análise do discurso oficial sobre humanização da assistência hospitalar. Cienc. Saude Colet., v.9, n.1, p.7-14, 2004b.

FABBRO, L. Limitações jurídicas à autonomia do paciente. Bioética, v.7, n.1, p.7-12, 1999.

GONZAGA, M.L.C.; ARRUDA, E.M. Fontes e significados de cuidar e não cuidar em hospital pediátrico. Rev. Latinoam. Enferm., v.6, n.5, p.17-26, 1998.

LAPLANTINE, F. Aprender antropologia. São Paulo: Brasiliense, 2003.

LIMA, R.A.G.; ROCHA, S.M.M.; SCOCHI, C.G.S. Assistência à criança hospitalizada: reflexões acerca da participação dos pais. Rev. Latinoam. Enferm., v.7, n.2, p.33-9, 1999.

MITRE, R.M.A. O brincar no processo de humanização da produção de cuidados pediátricos. In: DESLANDES, S.F. (Org.). Humanização dos cuidados em saúde: conceitos, dilemas e práticas. Rio de Janeiro: Fiocruz, 2006. p.283-300.

PEIRANO, M. A favor da etnografia. Rio de Janeiro: Relume-Dumará, 1995.

PINHEIRO, R. Cuidado como valor: um ensaio sobre o (re)pensar e a ação na construção de práticas eficazes de integralidade em saúde. In: PINHEIRO, R.; MATTOS, R.A. (Orgs.). Razões públicas para a integralidade em saúde: o cuidado como valor. Rio de Janeiro: IMS/UERJ/CEPESC/Abrasco, 2007. p.15-28. 
RABELLO, M.E.D.L. O que é protagonismo juvenil? 2002. Disponível em: <http:// www.cedeca.org.br/PDF/protagonismo_juvenil_eleonora_rabello.pdf > . Acesso em: 20 out. 2007.

SABATÉS, A.L.; BORBA, R.I.H. As informações recebidas pelos pais durante a hospitalização do filho. Rev. Latinoam. Enferm., v.13, n.6, p.968-73, 2005.

SOARES, J.C.R.S.; CAMARGO JR., K.R. A autonomia do paciente no processo terapêutico como valor para a saúde. Interface - Comunic., Saude, Educ., v.11, n.21, p.65-78, 2007.

TEIXEIRA, R.R. O acolhimento num serviço de saúde entendido como uma rede de conversações. In: PINHEIRO, R.; MATTOS, R.A. (Orgs.). Construção da integralidade: cotidiano, saberes e práticas em saúde. Rio de Janeiro: IMS/UERJ/CEPESC/Abrasco, 2007. p.89-112.

ALVES, C.A.; DESLANDES, S.F; MITRE, R.M.A. Desafíos de la humanización en el contexto del cuidado de la Enfermería Pediátrica de media y alta complejidad. Interface - Comunic., Saude, Educ., v.13, supl.1, p.581-94, 2009.

El presente artículo analiza las situaciones y contextos que propician o dificultan las relaciones de acogida y autonomía, comprendiendo los momentos y contextos en que el protagonismo y la co-responsabilidad se expresan en la relación entre enfermería, usuarios y sus acompañantes. Se utiliza el planteamiento cualitativo por medio de la perspectiva etnográfica y un periodo de observación de tres meses. El local de estudio ha sido la enfermería de Pediatría de un instituto de referencia al cuidado de la Salud de la Mujer, Niño y Adolescente y los sujetos fueron equipo de enfermería, usuarios y acompañantes. Los resultados indican que la acogida ha sido el principio más observado, mostrándose como elemento central de la discusión. Los niveles de autonomía, protagonismo y co-responsabilidad se relacionan al tiempo de internamiento, permitiendo establecer relaciones con los profesionales y adquirir conocimientos sobre la asistencia. Se concluye que existen huecos en la comprensión de un proyecto de humanización para el servicio contemplando gestión y cuidado.

Palabras clave: Humanización de la atención. Acogimiento. Autonomía. Protagonismo. Co-responsabilidad. 